\title{
Analysis of Hyperlipidemia Pattern in newly Diagnosed Diabetic Patients
}

\begin{abstract}
Objective: To analyze hyperlipidemia patterns among newly diagnosed young diabetic patients.

Study Design: A descriptive cross-sectional study. Place and Duration: Study was conducted in Nawaz Shareef Medical College and Rawalpindi Medical University from Jan 2017 and Jan 2018. Methodology: All the patients were young and newly diagnosed with Diabetes Mellitus. Data collection was done via non probability consecutive sampling included patients' demographics, past medical history, co-morbidities, and lab findings were assessed. SPSS version 24 was used to analyze data. P value $\leq 0.05$ was taken as significant. Results: Eighty patients were included in this study. Diabetic nephropathy, diabetic retinopathy, macrovascular complications, hyperglycemic hyperosmolar non-ketotic coma history, family history and hypertension were noted in $n=12(15 \%), n=6(7.5 \%), n=9(11.3 \%), n=1(1.3 \%), n=34(42.5 \%)$ and $n=11(13.8 \%)$ respectively. The mean hyperlipidemia, hypertriglyceridemia, of the patients was $4.54 \pm 0.52 \mathrm{mmol} / \mathrm{L}, 2.59 \pm 1.13 \mathrm{mmol} / \mathrm{L}$, $1.39 \pm 0.80 \mathrm{mmol} / \mathrm{L}, 1.03 \pm 0.59 \mathrm{mmol} / \mathrm{L}$ respectively. Conclusion: the study has shown that the prevalence of increased levels of triglycerides is more than increased LDL cholesterol levels among these patients. As it has been established that hypertriglyceridemia is a known risk factor for causing cardiovascular disorders among diabetic patients, it should be addressed and managed accordingly at the onset of diabetes.
\end{abstract}

Key words: Hyperlipidemia, Diabetes Mellitus, low density lipoproteins, high density lipoproteins, insulin.

DOI: $10.7176 / \mathrm{JMPB} / 62-08$

Publication date: December $31^{\text {st }} 2019$

\section{Introduction}

One of the leading causes of chronic morbidity and mortality is Diabetes mellitus ${ }^{1}$. Its prevalence is mushrooming many times in south Asia. Various factors contribute to this metabolic disorder including BMI, higher degree of genetic predisposition, increased levels of insulin resistance, and increased susceptibility to environmental insulin ${ }^{2}$. There is absolute deficiency of insulin secretion, action of insulin in relation to hyperglycemia, protein metabolism as well carbohydrate and lipids are deranged ${ }^{3}$. Various studies have shown that components of body composition such aa body fat and lipid profile are the culprits of increased prevalence of this disease. The abnormalities of lipid metabolism are more profound in diabetes mellitus as the pathway of lipid metabolism is influenced by deficiency and secretion of insulin ${ }^{4}$. Dyslipidemia is considered as a major risk factor in inducing cardiovascular diseases in diabetics. Increased triglycerides and LDL and decreased HDL lipoproteins are the main features of diabetic dyslipidemia ${ }^{5}$. In diabetic patients, the prevalence of hypercholesterolemia is not enhanced whereas the risk of mortality from coronary artery disease is increased ${ }^{6}$.

The guidelines from American Diabetic Association suggests stabilizing the serum triglycerides levels less than $150 \mathrm{mg} / \mathrm{dL}$, LDL levels less than $100 \mathrm{mg} / \mathrm{dL}$ and HDL greater than $40 \mathrm{mg} / \mathrm{dL}$ in males while $50 \mathrm{mg} / \mathrm{dL}$ in females ${ }^{7}$. The changes in lifestyle has made this situation indicated. It is to be kept in mind that metabolic derangements produced are reversible and preventable ${ }^{8}$.

In Pakistan, 7.1 million people are suffering from diabetes mellitus ${ }^{9}$. There is a prevalence rate of 18 $46 \%$. A special triad of symptomology seen more often is the hyperlipidemia, coronary artery disease. It enhances the severity of coronary artery disease ${ }^{10}$. Hence, this study was put forth to analyze the frequency of hypertriglyceridemia, and hyperlipidemia patterns in young patients that are recently diagnosed with diabetes mellitus.

\section{Methodology}

The study took place at Study was conducted Study was conducted in Nawaz Shareef Medical College and Rawalpindi Medical University from Jan 2017 and Jan 2018. The included participants were all newly diagnosed. Informed consent was taken from the patients and approval from ethics committee was taken. Data collection was done via consecutive sampling. It included patients' demographics, past medical history, co- 
morbidities, and lab findings. Fasting glucose levels were collected and viewed for LDL, Triglycerides and total cholesterol levels. The duration of fasting was minimum of 9 hours and maximum of 12 hours. The patients using lipid lowering agents or the ones who were having dietary restriction as well as obese patients were excluded from the study. Patients using beta blockers or diuretics and alcoholic patients were also excluded from the study. Triglycerides were termed high in the presence of greater than $1.7 \mathrm{mmol} / \mathrm{L}$ and high LDL was determined at a level of $2.59 \mathrm{mmol} / \mathrm{L}$. the analysis of data was done through SPSS version 23.

\section{Results}

Eighty patients were included in this study. The mean age of the patients was $38.28 \pm 4.37$ years. Diabetic nephropathy, diabetic retinopathy, macrovascular complications, hyperglycemic hyperosmolar nonketotic coma history, family history and hypertension were noted in $n=12(15 \%), n=6(7.5 \%), n=9(11.3 \%), n=1$ $(1.3 \%), n=34(42.5 \%)$ and $n=11(13.8 \%)$ respectively. Diabetes was noted type-I and type-II as $n=28(35 \%)$ and $\mathrm{n}=52(65 \%)$ respectively. Proteinuria was observed trace, +1 and +2 as $n=66(82.5 \%), n=10(12.5 \%)$ and $n=4$ $(5 \%)$ respectively. (Table. I).

The mean hyperlipidemia, hypertriglyceridemia, LDL, HDL, urea, creatinine, HbA1C, ALT, BSF and BSR of the patients was $4.54 \pm 0.52 \mathrm{mmol} / \mathrm{L}, 2.59 \pm 1.13 \mathrm{mmol} / \mathrm{L}, 1.39 \pm 0.80 \mathrm{mmol} / \mathrm{L}, 1.03 \pm 0.59 \mathrm{mmol} / \mathrm{L}$, $3.08 \pm 1.42 \mathrm{mmol} / \mathrm{L}, 97.23 \pm 4.82 \mu \mathrm{mol} / \mathrm{L}, 8.55 \pm 1.05 \mathrm{mmol} / \mathrm{L}, 49.50 \pm 2.85 \mathrm{units} / \mathrm{L}, 200.40 \pm 5.16 \mathrm{mg} / \mathrm{dL}$ and $313.78 \pm 7.32 \mathrm{mg} / \mathrm{dL}$ respectively. (Table. II).

Table. I

\begin{tabular}{|l|c|}
\hline \multicolumn{1}{|c|}{ Variables } & Presence \\
\hline Age & $38.28 \pm 4.37$ \\
\hline Diabetic nephropathy & $\mathrm{n}=12(15 \%)$ \\
\hline Diabetic retinopathy & $\mathrm{n}=6(7.5 \%)$ \\
\hline Macrovascular Complications & $\mathrm{n}=9(11.3 \%)$ \\
\hline $\begin{array}{l}\text { Hyperglycemic Hyperosmolar Non- } \\
\text { ketotic Coma history }\end{array}$ & $\mathrm{n}=1(1.3 \%)$ \\
\hline Family History & $\mathrm{n}=34(42.5 \%)$ \\
\hline Hypertension & $\mathrm{n}=11(13.8 \%)$ \\
\hline Diabetes & $\mathrm{n}=28(35 \%)$ \\
\hline Type-I & $\mathrm{n}=52(65 \%)$ \\
\hline Type-II & $\mathrm{n}=66(82.5 \%)$ \\
\hline Proteinuria & $\mathrm{n}=10(12.5 \%)$ \\
\hline Trace & $\mathrm{n}=4(5 \%)$ \\
\hline+1 & \\
\hline+2 &
\end{tabular}

Table. II

\begin{tabular}{|l|c|}
\hline \multicolumn{1}{|c|}{ Variables } & Mean \pm S.D \\
\hline Hyperlipidemia (mmol/L) & $4.54 \pm 0.52$ \\
\hline Hypertriglyceridemia (mmol/L) & $2.59 \pm 1.13$ \\
\hline LDL (mmol/L) & $1.39 \pm 0.80$ \\
\hline HDL (mmol/L) & $1.03 \pm 0.59$ \\
\hline Urea (mmol/L) & $3.08 \pm 1.42$ \\
\hline Creatinine ( $\boldsymbol{\mu m o l} / \mathbf{L})$ & $97.23 \pm 4.82$ \\
\hline HbA1C (mmol/L) & $8.55 \pm 1.05$ \\
\hline ALT (units/L) & $49.50 \pm 2.85$ \\
\hline BSF (mg/dL) & $200.40 \pm 5.16$ \\
\hline BSR (mg/dL) & $313.78 \pm 7.32$ \\
\hline
\end{tabular}

\section{Discussion}

One of the most common chronic diseases is diabetes mellitus which ranks among the top five causes of mortality around the world, says Padmini $\mathrm{O}$ et al ${ }^{11}$. it is said to be equivalent to coronary heart disease in terms of risk factor for causing cardiovascular complications. A major known risk factor for these vascular 
complications is dyslipidemia. Hence a study was done to prove the strong association between Dyslipidemias and Diabetes mellitus type 2. It was a one-year cross sectional prospective study upon 100 patients proving that there is remarkably significant and hence considerable association of dyslipidemia with Diabetes Mellitus type 2.

A hypothesis was made suggesting the interrelationship of transmembrane transport of cholesterol is related to the development of type 2 diabetes by Besseling $\mathrm{J}$ et al ${ }^{12}$. hence the association between diabtes type 2 and familial hypercholesterolemia was testes in a cross-sectional study where the DNA testing of all patients was done. The study demonstrated that prevalence of diabetes mellitus type 2 in patients having familial hypercholesterolemia was found to be markedly reduced than was found between unaffected relatives with some variation due to type of mutation. If this association is confirmed in further longitudinal analysis, it will rise the suspicion of causal relation between LDL receptor mediated transmembrane cholesterol transport and diabetes type 2 .

As dyslipidemia is a known risk factor for coronary artery disease in type 2 diabetes mellitus, a post hoc analysis was done by Watts GF ${ }^{13}$ in diabetic patients. The analysis of lipid regulating trials demonstrated that increase in serum HDL with a decrease in LDL along with a statin or rise in serum HDL with decrease in triglycerides with a fibrate reduces the risk of incidence of coronary diseases. This absolute reduction is high enough to make lipid lowering therapy cost effective among these patients. Hence ameliorating the dyslipidemias, improves the outcome of coronary diseases and reduces the risk of their occurrence.

When patterns of dyslipidemia were observed in patients of Lahore having Diabetes mellitus by Naheed $\mathrm{T}$ et al ${ }^{14}$, it was seen that among patients having diabetes for less than ten years, the level of serum cholesterol was $191.72 \pm 5.72$ whereas it was found to be $213.11 \pm 6$.70in patients having diabetes for more than 10 years. The level of serum triglyceride among patients with shorter duration of diabetes was $191.83 \pm 8.05$ and HDL level was $36.25 \pm 0.45$ and LDL was $127.1 \pm 3.99$. among patients having diabetes for longer duration $>10$ years, triglycerides were $210.04 \pm 8.90$ and HDL was $35.57 \pm 0.60$ and LDL was $147.5 \pm 5.20$. out of 100 patients, 58 patients had hypertension. It is observed that the duration of diabetes affects greatly the incidence of dyslipidemia.

The major cause of morbidity and mortality in patients with diabetes mellitus is cardiovascular diseases 15. The known risk factors proceed the same way in both diabetic and non-diabetics, thus the reasonable explanation have been made for increased atherothrombosis in diabetes mellitus type 2. Among the characteristics known for diabetes mellitus type 2, one recently focused factor in research is hyperglycemia. It has found that even in the absence of diabetes mellitus, the increased glucose levels are associated with higher risk of cardiovascular diseases. It has been shown by various studies that include diabetics and non-diabetics that hyperglycemia can't be ignored as risks factor for cardiovascular diseases, as said by Laakso $\mathrm{M}^{16}$. The harmful effects of glucose begin to produce their effects at the glucose range of $<6.1 \mathrm{mmol} / \mathrm{l}$. whereas in diabetes, the effect of hyperglycemia works in an exponential manner. It has been established that long term complications of diabetes can be prevented by good glycemic control. Similarly, intensive treatment of hypertension and hypercholesterolemia in patients with diabetes also improves the outcomes.

There are various studies showing the effectiveness of intensive management of lipid disorders in diabetics in order to reduce the complications. Ahmad $\mathrm{N}$ et al ${ }^{17}$ performed a study to determine whether patients having good glycemic control have better lipid profile than the ones that have poor glycemic control. Out of 78 diabetic patients having hypertriglyceridemia, 46 patients had poor glycemic control i.e. HbA1c $>8 \%$. It was established that good glycemic control affects the lipid levels in patients with diabetes type 2 . There must be sufficient educating of patients in motivating them towards lipid lowering therapy ${ }^{18}$.

Similarly, the clinical trials done by Watts GF ${ }^{19}$ and Siddiqui AH et al ${ }^{20}$ on association between hyperglycemia and risks of coronary disease as a result of dyslipidemia states that in order to achieve better results in control of diabetes and prevent its complications, the control of lipid levels in the blood cannot be neglected.

\section{Conclusion}

The study has shown that the prevalence of increased levels of triglycerides is more than increased LDL cholesterol levels among these patients. As it has been established that hypertriglyceridemia is a known risk factor for causing cardiovascular disorders among diabetic patients, it should be addressed and managed accordingly at the onset of diabetes. 


\section{References}

1-Gustafsson I, Brendorp B, Seibaek M, Burchardt H, Hildebrandt P, Kober L. The influence of diabetes and the diabetes - gender interaction on the risk of death in patients who were hospitalized with congestive heart failure. J Am Coll Cardiol 2014; 43(5): 771-77.

2-Basit A, Shera AS. Prevalence of metabolic syndrome in Pakistan. MetabSyndrRelatDisord 2008; 6(3): 17175.

3-Feher MD. Diabetes preventing coronary heart disease in high risk group. Heart 2010; 90(4): 18-21

4-American Diabetes Association Dyslipidemia management in adults with diabetes. Diabetes Care 2004; 27(Suppl-1): S68-S71.

5-Jayarama N, Reddy M, Lakshmaiah V. Prevlence and pattern of dyslipidemia in type-2 diabetes mellitus patients in a rural tertiary care centre, South India. GJMEDPH 2012; 1(3): 24.

6-Huang KC, Chen CC, Su YC, Lin JS, Chang CT, Wang TY. The relationship between stasis stagnation constitution and peripheral arterial disease in patients with type-2 diabetes. Evid Based Complement. Alternat Med 2014; 2014:6

7-Abou-Seif MA, Youssef AA. Evaluation of some biochemical changes in diabetic patients. Clin Chim Acta 2009; 346: 161-70.

8-Mooradian AD. Dyslipidemia in type-2 diabetes mellitus. Nat Rev Endocrinol 2009; 5: 150-59.

9-Sohail SMA, Faisal Z, Umar J. Metabolic syndrome in type-2 diabetes mellitus. Pak J Med Sci 2006; 22: 295 99.

10-Agrawal Y, Goyal V, Chugh K, Shanker V, Singh AA. Types of dyslipidemia in type-2 diabetic patients of Haryana region. Sch J App Med Sci 2014; 2(4): 1385-92.

11-Padmini O, Devi MR, Sumanth V, Sridviya V. ASSOCIATION OF DYSLIPIDEMIAS WITH TYPE 2 DIABETES MELLITUS: A PROSPECTIVE STUDY. J of Evolution of Med and Dent Sci. 2015; 4(76) : 13204

12-Besseling J, Kastelein JJP, Defesche JC, Hutten BA, Hovingh GK. Association Between Familial Hypercholesterolemia and Prevalence of Type 2 Diabetes Mellitus. JAMA. 2015;313(10):1029-1036.

13- Watts GF. Coronary disease, dyslipidaemia and clinical trials in type 2 diabetes mellitus

14-Naheed T, Khan A, Masood G, Yunus BB, Chaudhary MA. DYSLIPIDEMIAS IN TYPE II DIABETES MELLITUS PATIENTS IN A TEACHING HOSPITAL OF LAHORE, PAKISTAN. Chaudhry Pak J Med Sci. 2003; 19(4): 283-286.

15-Laakso M. Hyperglycemia and cardiovascular disease in type 2 diabetes. Diabetes. 1999; 48(5): 937-942

16-Laakso M. Perspectives in Diabetes Hyperglycemia and Cardiovascular Disease in Type 2 Diabetes. DIABETES. 1999; 48.

17-Ahmad N, Khan J, Siddiqui TS. FREQUENCY OF DYSLIPIDAEMIA IN TYPE 2 DIABETES MELLITUS IN PATIENTS OF HAZARA DIVISION. J Ayub Med Coll Abbottabad. 2008;20(2)

18-Kandula R., Shegokar VA. Study of lipid profile in patients with type-2 diabetes mellitus J Health Sci 2013; 1(1): 23-26.

19-Watts GF. Coronary disease, dyslipidaemia and clinical trials in type 2 diabetes mellitus. Practical Diabetes Int. 2000; 17(2): $54 \pm 59$.

20- Siddiqui AH, Ahmad I, Hafeez M, Khadim R, Aziz S, Iqbal T et al. HYPERLIPIDEMIA PATTERNS IN NEWLY DIAGNOSED YOUNG DIABETIC SOLDIERS: A DESCRIPTIVE CROSS-SECTIONAL STUDY. Pak Armed Forces Med J. 2018; 68 (Suppl-1): S5-S9 